\title{
O PAPEL DO BNDES NA INTEGRAÇÃO DO TERRITÓRIO BRASILEIRO*
}

\author{
Hélio Caetano Farias
}

Resumo: Este artigo analisa o papel do BNDES na industrialização e na integração do território brasileiro. Criado na década de 1950, o Banco tornou-se uma das principais referências de planejamento da burocracia estatal e imprescindível aos principais projetos nacionais das mais diversas orientações. Na década de 1990, com a globalização, o BNDES foi estratégico na elaboração e operacionalização de um quadro normativo favorável à internacionalização do território.

Palavras-chave: BNDES, empresas de consultoria, privatização, uso corporativo do território.

\section{A THE ROLE OF BNDES TO USE THE BRAZILIAN TERRITORY}

\begin{abstract}
This article explores the role of BNDES in the industrialization and integration of the Brazilian territory. Created in the 1950s, the Bank has become a major reference for planning the state bureaucracy and vital, to key national projects from different orientations. In the 1990s, with globalization, BNDES was strategic in the development and operationalization of a framework conducive to the internationalization of the territory.
\end{abstract}

Keywords: BNDES, consultancy companies, privatizations, corporate use of territory.

\section{Introdução}

O presente texto visa contribuir com a interpretação sobre uso do território brasileiro a partir da análise do Banco Nacional de Desenvolvimento Econômico e Social - BNDES. A escolha desta instituição se deve a sua importância no planejamento, financiamento e execução dos principais projetos de desenvolvimento vivenciados pelo país desde meados do século $X X$.

As preocupações com a industrialização, com a integração do território e com a superação do subdesenvolvimento fundamentaram a criação do Banco em 1952, e, por conseguinte, orientaram suas opções políticas. Em pouco tempo, o $\mathrm{BNDE}^{1}$ se

\footnotetext{
${ }^{1}$ Só em 1982, com a incorporação dos recursos do
} Fundo de Investimento Social (Finsocial), o então tornou uma das principais referências de planejamento da burocracia estatal e, imprescindível, aos principais projetos nacionais das mais diversas orientações.

O Banco, em virtude da sua importância, foi objeto de vários estudos, sobretudo os que se preocupam em analisar o processo de industrialização e a formação do mercado interno. Dentre estes estudos, diversas periodizações foram propostas, como nos trabalhos de Sheila Najberg (1989), Dulce Monteiro Filha (1994[1989]), Ana Alem (1997), Cláudia Curralero (1998), Adriana Diniz (2004), Gilberto Silva Jr. (2004), além, é claro, das periodizações

BNDE agregou a letra $\mathrm{S}$ a sua sigla, passando a se chamar BNDES. Adota-se aqui essa perspectiva quando se diz BNDE ou BNDES.

* Título da dissertação O BNDES e as privatizações no uso do território brasileiro, orientada pela $\operatorname{Prof}^{\mathrm{a}} \mathrm{Dr}^{\mathrm{a}}$ Adriana Maria Bernardes da Silva, no Programa de Pós-graduação do Departamento de Geografia do Instituto de Geociências da Unicamp, e defendida em 2008. 
propostas pelo próprio banco, como, por exemplo, no livro comemorativo de seu cinquentenário BNDES: 50 Anos de Desenvolvimento (2002).

Com base nos trabalhos citados, encaminhamos uma proposta de periodização que, a princípio, parte de quatro grandes períodos. O primeiro, entre 1952 e 1964, ressalta o papel do BNDE no financiamento dos macrossistemas de energia e transporte; o segundo, entre 1965 e 1981, caracteriza a importância do BNDE na ampliação dos circuitos produtivos industriais, principalmente com o financiamento dos setores privados nacionais; o terceiro, entre 1982 e 1989, evidencia-se a inflexão das prioridades históricas do BNDES frente ao processo de globalização, com destaque para a estratégia de integração competitiva nos mercados internacionais. Por fim, o quarto período, em vigor desde 1990, o BNDES se destaca como um dos principais responsáveis pela Política de Privatização.

Nas linhas a seguir busca-se analisar, a partir desta proposta de periodização, as principais transformações na formação socioespacial brasileira, tendo por base a dinâmica de financiamento do BNDES.

\section{o BNDE e o financiamento dos macrossistemas de energia e transporte}

Este primeiro período compreende desde a criação do BNDE, em 1952, até meados da década de 1960. Como já levantado pela bibliografia citada, existem diversas nuanças neste intervalo de tempo, o que permitiria outras subdivisões. No entanto, o que se espera enfatizar é a preocupação do Estado brasileiro em expandir territorialmente os macrossistemas técnicos, ${ }^{2}$ mormente os de transporte e de energia, e, assim, garantir as bases da integração territorial e do processo de industrialização.

No intuito de levantar os principais obstáculos territoriais que dificultavam o desenvolvimento de atividades capitalista em termos industriais, o segundo governo de Getúlio Vargas (1951-1954), criou o Programa de Reaparelhamento Econômico. ${ }^{3}$ Tal programa se fundamentou, primeiramente, na realização de estudos sobre as condições das infraestruturas nacionais e, a posteriori, nos mecanismos necessários à obtenção de financiamentos, indispensáveis a realização dos projetos traçados.

A dimensão dos projetos, aliada a pouca capacidade de financiamento interno, fez com que o governo brasileiro recorresse aos empréstimos externos para viabilizá-los. O Eximbank (Export-Import Bank) e o Banco Mundial foram as instituições fornecedoras de grandes quantidades de capital. Destas negociações entre os agentes externos e o governo brasileiro surgiu Comissão Mista Brasil-Estados Unidos (CMBEU).

De acordo com Dias (1996), a criação do BNDE está intimamente ligada às iniciativas desenvolvidas no plano da CMBEU para a execução de um conjunto de projetos de investimento, ${ }^{4}$ uma vez que o Banco

\footnotetext{
2 Entende-se por macrossistemas técnicos o que Santos (1996, p. 142) descreve como "aqueles sistemas de técnicas sem os quais os outros sistemas técnicos não funcionam", que se materializam em barragens, ferrovias, rodovias, portos, aeroportos, sistemas de telecomunicações etc., constituindo, assim, o "fundamento material das redes de poder".

${ }^{3}$ Criado a partir da Lei 1.474 , de 26 de novembro de 1951, e reformado na Lei 1.518 , de 24 de dezembro de 1951.

${ }^{4}$ Dias (1996, p. 82) discorre sobre essa questão nos seguintes termos: "A criação do Banco
} 
visava primordialmente financiar os projetos que eliminariam os "entraves das ações de crescimento produtivo", bem como "pretendia-se atuar diretamente nos fatores que impulsionassem a independência de alguns setores produtivos, aliando-se diretamente à política de substituição de importações" (SILVA JR., 2004, p. 91).

Além dos estudos da CMBEU, outra instituição que teve destaque no delineamento das atuações do BNDE foi a Comissão Econômica para a América Latina (Cepal), um órgão das Nações Unidas responsável pela elaboração de estudos e políticas de desenvolvimento para os países da América Latina. O convênio com a Cepal foi firmado em 1953, com a criação do Grupo Misto de Estudos. Este grupo produziu uma série de estudos - fundamentados em um amplo levantamento estatístico da situação econômica e produtiva do território nacional - que subsidiou a elaboração de projetos. Ademais, a parceria BNDE-Cepal promoveu um conjunto de cursos com intelectuais renomados da época, como Celso Furtado, Roberto Campos e Anísio Teixeira (SILVA JR., 2004). O objetivo era formar quadros técnicos especializados na problemática do desenvolvimento econômico. ${ }^{5}$

A articulação do BNDE com a Cepal possibilitou uma compreensão mais apurada

Nacional de Desenvolvimento Econômico prende-se às iniciativas desenvolvidas no plano da Comissão Mista Brasil-Estados Unidos para a execução de um conjunto de projetos de investimento. Após negociações difíceis com o governo norteamericano, a Comissão foi finalmente instalada em julho de 1951, com o propósito de elaborar projetos para financiamento conjunto pelo governo brasileiro e por agências norte-americanas, cujos recursos proviriam basicamente do Banco Mundial e do Eximbank, enquanto a contrapartida brasileira seria constituída principalmente por adicionais ao imposto de renda de pessoas físicas e jurídicas".

${ }^{5}$ Em 1953, foi ministrado pela CEPAL, no Rio de Janeiro, o Curso de Treinamento em Problemas de Desenvolvimento Econômico. das peculiaridades da dinâmica de acumulação capitalista no Brasil. A formação do Grupo Misto BNDE-Cepal buscou um planejamento mais consistente das situações socioespacial brasileira (DIAS, 2004). O programa de investimentos elaborado pelo Grupo Misto não chegou a entrar em vigor, contudo serviu de um importante subsídio teórico e operacional ao Plano de Metas (1956-1961).

O BNDE situava-se no centro desse debate, pois desde sua criação acumulava experiências como um centro de análise para os programas do governo, sendo, portanto, imprescindível à elaboração, gerenciamento e financiamento dos projetos governamentais. O Plano de Metas consistia em um conjunto de objetivos para economia nacional, tendo por base o levantamento e a análise minuciosa das situações econômico-produtiva do território nacional. Os setores prioritários eram, de um lado, transporte e energia e, de outro, a implantação de indústrias de base.

Os esforço dos planos governamentais de meados do século $X X$, sobretudo com o governo de Juscelino Kubitschek (1956-1961), expressavam um momento de "ajuste entre as ideologias geográficas e as políticas territoriais do Estado é total e explícito. O discurso e a materialização física das metas caminham em consonância com a tarefa estatal de construir o país objetivando-se agressivas políticas territoriais, num esforço de produção de espaços ímpar na história brasileira" (MORAES, 2002, p. 125).

O peso das divisões territoriais pretéritas se fez presente com o processo de industrialização. Os financiamentos do BNDE, no intuito de acelerar a industrialização, vieram reforçar uma estrutura produtiva 
territorialmente concentrada na região sudeste, mormente entre os estados do Rio de Janeiro e São Paulo. O Mapa 1 indica essa tendência.

Mapa 1 - Desembolsos do BNDE entre 1952 e 1964

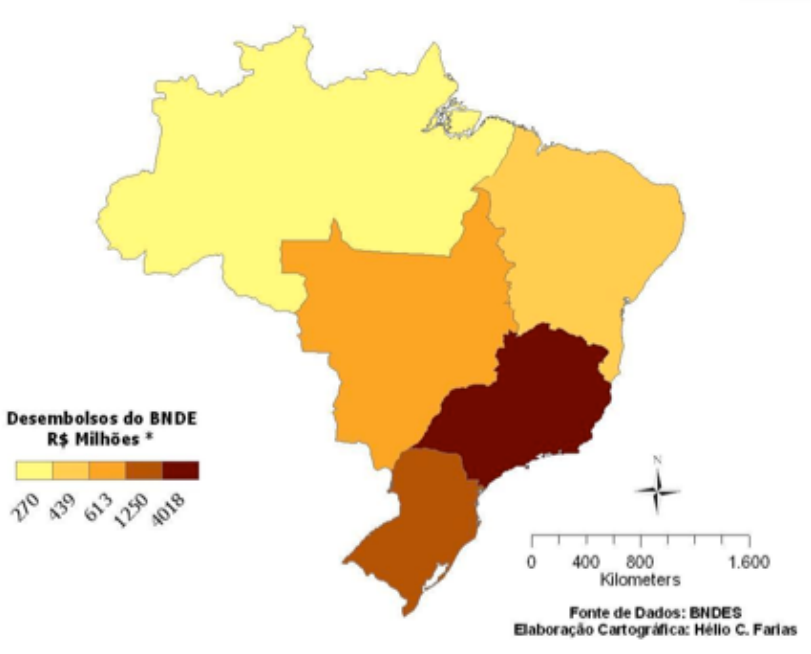

A concentração de financiamentos na região centro-sul responde aos imperativos da constituição e expansão do meio técnico-científico-informacional (SANTOS, 1996). Evidencia-se, nestes primeiros períodos da industrialização nacional, a formação de uma Região Concentrada. ${ }^{6}$ Para Santos (1993), a região concentrada coincide com a área contínua de manifestação do meio técnico-científico-informacional, ao passo que nas demais regiões do país tal manifestação ocorre de maneira mais seletiva e pontual.

Segundo Becker e Egler (1998), os resultados desses primeiros planos de desenvolvimento, sobretudo com o Plano de Metas, foram duplos. De um lado, acentuou a histórica concentração econômica e produtiva no sudeste por meio de investimentos nos macrossistemas técnicos e, de outro lado, modernizou e ampliou a integração territorial

\footnotetext{
${ }^{6}$ A Região Concentrada, segundo Santos e Silveira (2001, p. 27), abrange os estados do Rio Grande do Sul, Santa Catarina, Paraná, São Paulo, Rio de Janeiro, Minas Gerais e Espírito Santo.
}

com as áreas periféricas, robustecendo as dimensões do mercado interno.

Tais modernizações territoriais reorganizaram as relações internas na formação socioespacial brasileira, dividida, agora, em áreas em que este meio técnico-científico se difunde de maneira relativamente continua e áreas onde sua presença ocorre de forma pontual e seletiva.

\section{O BNDE e a ampliação dos circuitos produtivos industriais}

Neste segundo período, entre meados da década de 1960 e o alvorecer da década de 1980, destaca-se o papel do BNDE no financiamento do desenvolvimento industrial. Amplia-se, também, a transnacionalização do território brasileiro em virtude da crescente participação das grandes empresas multinacionais nos sistemas produtivos nacionais. Alargam-se, assim, novos vínculos do país com a divisão internacional do trabalho.

Com a vigência dos governos militares, o planejamento, pela via autoritária, buscava criar as condições, sobretudo com os I e II PND, para o desenvolvimento interno das atividades intensivas em tecnologias avançadas, como uma forma de redução da dependência externa e como um instrumento que visava transformar o país numa potência regional.

De acordo com Becker e Egler (1998), o território era visto como a base técnica do processo e buscava-se, portanto, dotá-lo de operacionalidade e funcionalidade para garantir a reprodução ampliada do capital e promover a integração nacional. As noções de modernização e desenvolvimento: 
[...] perdem seu componente social e político, passando a qualificar apenas os aparatos produtivos e as infraestruturas [...] pode-se dizer que a ocupação e ordenamento do espaço atuaram como eixo estruturador do planejamento governamental no período militar (MORAES, 2002, p. 126-127).

No I Plano Nacional de Desenvolvimento (I PND), entre 1972-1974, - BNDE passou por uma série de transformações. ${ }^{7}$ A primazia do setor privado nacional na política do governo orientou a criação de instituições para apoiá-lo e dirigi-lo por meio da participação acionária e de programas específicos de financiamentos (MARTINS, 1991).

É neste contexto que surge o Sistema BNDE, a partir da criação de três subsidiárias: a Insumos Básicos S.A. (Fibase), a Investimentos Brasileiro S.A (Ibrase) e a Mecânica Brasileira S.A. (Embramec). O intuito, segundo O BNDES (2002, p. 94), era o de "atuar no mercado de capitais, de modo a ampliar as formas de capitalização das empresas brasileira".

Outro elemento de extrema importância foi a incorporação, em 1974, dos recém-criados Programa de Integração Social (PIS) e Programa de Formação do Patrimônio Público (PASEP), às fontes de recursos do BNDE. O BNDE passou a ter, assim, uma maior liberdade em seus gastos, bem como na definição da estrutura de seu financiamento. Subjacente a estas medidas, a instituição aproximou-se mais da empresa

\footnotetext{
7 Em 1971, o Banco deixa de ser uma autarquia e passa a ser uma empresa pública. Tal mudança proporcionou uma maior liberdade ao Banco para a contratação de pessoal e maior flexibilidade na obtenção e aplicação dos recursos. Implícito a esta medida, estava a tentativa de fortalecer a estrutura política e institucional do Banco (MARTINS, 1991).
}

privada nacional e internacional, deixando num segundo plano os investimentos nas empresas estatais, assumindo deliberadamente uma política antiestatizante. O BNDE tornou-se, assim, uma espécie de demiurgo do empresariado nacional (MARTINS, 1991, p. 105).

$$
\text { No II Plano Nacional de }
$$
Desenvolvimento (II PND), entre 1974 -1979, o BNDE despontava como a principal instituição para a sua operacionalização. A responsabilidade do Banco residia: no fornecimento de crédito para os setores públicos e privados; na construção da capacidade científica nacional; no financiamento do desenvolvimento tecnológico; no incentivo a intensificação das exportações de manufaturas nacionais. Segundo Pinto (2004, p. 52), "a publicação do II Plano Nacional de Desenvolvimento (II PND) em 1974 marcou também uma fase de apogeu para o então Banco Nacional do Desenvolvimento Econômico (BNDE) como instância mista de formulação e de implementação de políticas de industrialização no Estado brasileiro".

Desde sua criação, na década de 1950, até meados da década de 1960, o BNDE se caracterizou como uma instituição ativa no financiamento dos macrossistemas técnicos e das indústrias de base. A partir de 1964, o BNDE, mesmo continuando com a função de uma instituição de crédito de longo prazo, sofreu uma guinada nas suas estratégias de financiamento; a partir de então, o Banco priorizou a concessão de financiamentos para o setor privado.

A estratégia política de favorecer a industrialização por substituição de importações pode ser interpretada como uma 
condição imprescindível, mas não suficiente para alcançar 0 tão almejado desenvolvimento. A inserção subordinada do país no sistema econômico internacional atuava (e ainda atua) como um agravante em relação ao problema da dependência externa. Dito de outra forma, a interpretação das transformações históricas, impulsionadas pela industrialização, não pode ser pensada como uma variável externa às estruturas políticas e econômicas da divisão internacional do trabalho.

De acordo com Belluzzo (2002), o II PND foi o último grande esforço de integração e modernização da estrutura industrial brasileira. Suas metas, no entanto, não foram compatíveis com a capacidade interna de financiamento. Fato que fez com que o governo recorresse excessivamente ao capital externo. A maioria dos projetos financiados revelou a incapacidade de gerar divisas suficientes para pagar as dívidas contraídas no exterior.

Nesse sentido, Santos e Silveira (2001, p. 50) afirmam que esta última onda industrializante significou a reprodução ampliada daquilo que fora feito anteriormente, de modo que "tudo cresce ainda mais, porém no mesmo sentido: uma produção industrial extravertida, um maior endividamento, maior penetração das firmas estrangeiras". Concomitantemente a esse processo, ocorreu uma intensa centralização geográfica da produção e da riqueza na região concentrada (SANTOS, 1993), coincidindo com a área mais contigua de expansão do meio técnico-científico.

O Mapa 2 mostra a concentração territorial dos desembolsos do BNDES.
Mapa 2 - Desembolsos do BNDE entre 1965 e 1981

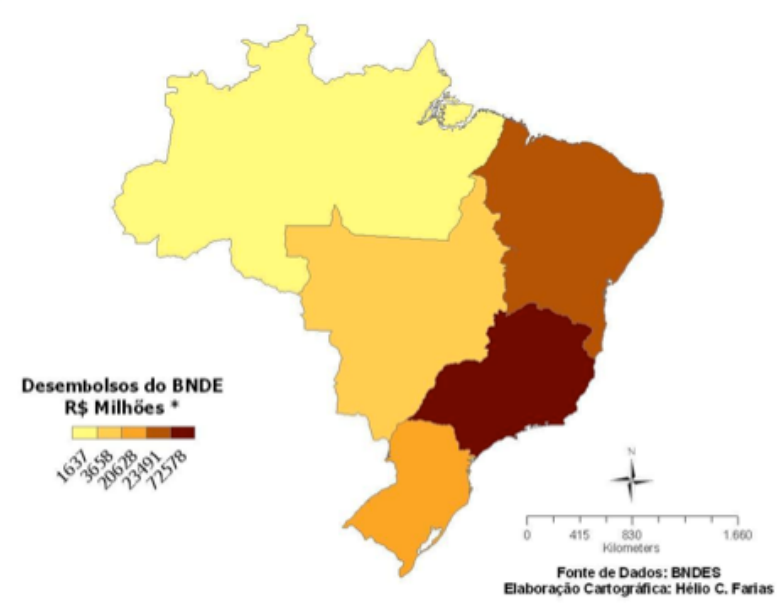

A configuração territorial brasileira conheceu uma vertiginosa transformação, com os intensos processos de industrialização e urbanização, no entanto, a essência dos problemas de subdesenvolvimento permaneceu, pois o país não conseguiu superar seus principais problemas socioespaciais. $^{8}$

Segundo Belluzzo (2002), a partir da década de 1980, inicia-se um conjunto de reformas, de cunho neoliberal, no Estado brasileiro. Tais reformas se fundamentavam numa crítica ao modelo de industrialização brasileiro, via substituição de importações, que, nesta visão, representava uma tendência à obsolescência, à ineficiência, à falta de competitividade externa e à estatização econômica ao extremo.

\footnotetext{
8 Francisco de Oliveira (2003) sustenta que a acelerada transformação da estrutura produtiva, advinda com a industrialização, não anulou as articulações entre o "velho" e o "novo" na formação social brasileira, que, segundo ele, criou uma situação paradoxal, pois não estava marcada nem pelo signo da exclusão à apartheid, nem indicava elementos para uma revolução social.
} 


\section{O BNDES e as concepções de integração competitiva}

Este terceiro período, entre 1982 e 1989, retrata a reorientação das atividades do Banco, tendo em vista a maior aproximação da burocracia estatal com a lógica administrativa das empresas privadas. Em termos políticos, representou a subordinação das decisões de financiamento a critérios mais técnicos do que políticos. ${ }^{9}$

Concomitante a essa nova orientação, o BNDE, em 1982, passou a gerir os recursos do Fundo de Investimento Social (Finsocial). A instituição, a partir daí, passou a chamar BNDES e agregou mais uma responsabilidade: a de ser, também, um agente promotor do desenvolvimento social. Tal responsabilidade aumenta, ainda mais, a função pública da instituição, uma vez que são os recursos destinados à população mais pobre que estão financiando as diretrizes de desenvolvimento elaboradas pelo Banco.

O BNDES, ao longo da década de 1980, redefiniu a sua inserção na economia brasileira. A exaustão da estratégia de desenvolvimento pautada na política de substituição de importações e no forte endividamento externo deflagrou uma forte crise econômica. Por conseguinte, como discutido por Monteiro Filha (1994), o Banco não apresentava diretrizes bem claras de suas prioridades políticas e de financiamento; sua atuação priorizou o "auxílio" econômico e financeiro às empresas em crise. Mourão $(1994$, p. 5) é enfático ao afirmar que, com o

\footnotetext{
9 Segundo Silva Jr. (2004), as políticas territoriais do Banco começaram a marginalizar os grandes financiamentos nos macrossistemas técnicos e, em contrapartida, aumentaram os investimentos nas cidades, notadamente em obras de transportes urbanos como, por exemplo, os financiamentos de obras do metrô no Rio de Janeiro e de trens em São Paulo e no Rio de Janeiro, além da continuidade dos financiamentos para ampliação da malha rodoviária no país.
}

fim do II PND, o BNDES não "dava conta da nova realidade. Não havia uma linha clara de ação: as decisões de enquadramento dos pedidos de financiamento eram tomadas caso a caso numa Comissão de Prioridades, sem nenhum plano, documento ou parâmetros que norteassem suas decisões, a não ser a experiência de seus membros, executivos e técnicos altamente preparados em questões setoriais".

Em síntese, neste novo contexto, o BNDES atuou em três frentes principais: a) continuidade e finalização dos financiamentos propostos pelo II PND; b) concessões de crédito para o setor exportador, no intuito de gerar superávits comerciais; c) propugnar um processo de adequação e ajustes fiscais nos setores públicos e privados, através de seus programas saneamento financeiro (CURRALERO, 1998).

O Mapa $3^{*}$ mostra os desembolsos do BNDES neste terceiro período de nossa periodização.

Mapa 3 - Desembolsos do BNDES entre 1982 e 1989

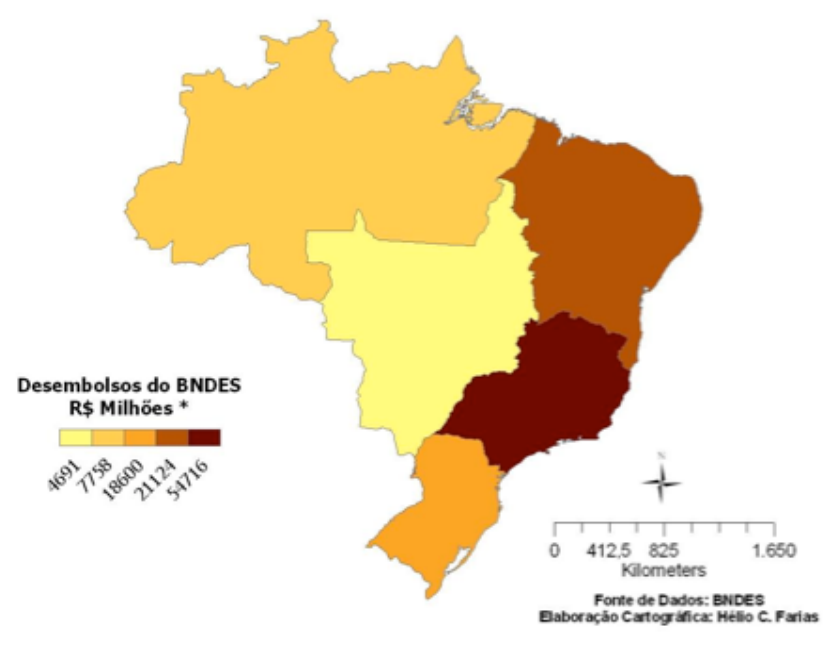

\footnotetext{
* O estado do Tocantins foi desmembrado de Goiás em 1988. Para a elaboração desse mapa, mantivemos a antiga divisão regional, sem o desmembramento. No ano de 1989, o desembolso no Tocantins foi equivalente a R\$ 79.641.899 (segundo valores médios de 2002).
} 
O processo de reformulação de suas diretrizes, em curso na década de 1980, mudou seu ideário, sendo este um movimento precursor e impulsionador de concepções liberalizantes como estratégia de desenvolvimento para o país.

O BNDES passou a adotar a prática do planejamento estratégico, mediante a elaboração de cenários prospectivos (BNDES, 2002). O cenário Integração Competitiva ${ }^{10}$ serviu de referência para a elaboração do Plano Estratégico 1988-1990. Dentre as novas diretrizes do Banco, destacam-se os seguintes pontos: ${ }^{11}$

a) O estilo de crescimento deve se voltar para a integração competitiva do Brasil na economia mundial e para a integração de toda a nação;

b) Superação dos pontos de estrangulamento na infraestrutura de energia e de transportes;

c) Participação do setor privado em investimentos hoje sob a responsabilidade do setor público;

d) Fortalecimento financeiro e patrimonial do Sistema BNDES, através da adequação das fontes e novas formas de aplicação de maior retorno;

\footnotetext{
${ }^{10}$ De acordo com Mourão (1994, p. 12), o cenário Integração Competitiva foi baseado em três aspectos elaborados no cenário anterior (cenário Retomada), a saber: "[a] a identificação de que componentes autônomos de demanda privada seriam os responsáveis por um novo ciclo de crescimento, abandonando a ideia de um desenvolvimento liderado pelo Estado; [b] a visão do mercado externo como importante indutor do desenvolvimento, e não como concorrente da produção voltada a atender às necessidades internas; e [c] a modernização empresarial visando à competitividade como um objetivo essencial para o desenvolvimento econômico e social, e não apenas a expansão de capacidade geradora de emprego".

11 Plano Estratégico do Sistema BNDES (BNDES, 1988 apud COSTA, 2003).
}

e) Racionalização organizacional e dos fluxos operacionais do Sistema BNDES no curto prazo;

f) Modernização do Sistema BNDES a partir de uma concepção empresarial adaptada às exigências do novo estilo de crescimento.

Nota-se a emergência de um novo marco normativo condizente com as transformações decorrentes do período histórico. O BNDES encarna esta nova burocracia, cujo fundamento reside na tentativa de empiricizar uma nova racionalidade na administração pública, e, consequentemente, na organização do território.

O BNDES, assim, situa-se como um locus de redefinição da política de Estado. Suas proposições serviram de base para que o Estado brasileiro começasse a realizar suas primeiras privatizações. Tal prática estava consubstanciada a um novo rearranjo normativo e territorial para que o Brasil pudesse se inserir ativamente na "nova" fase de internacionalização do capital e, por conseguinte, pudesse acompanhar o ritmo das transformações políticas, econômicas, tecnológicas pelas quais passavam diversos países do mundo.

\section{O BNDES e a política de privatização}

Neste quarto período, a partir do início da década de 1990, o BNDES destacase como uma instituição central do processo de privatização, contribuindo, assim, para intensificar o uso corporativo do território.

A "nova" fase de internacionalização do capital erigida entre as décadas de 1970 e 
1980 fundamenta-se na existência do meio técnico-científico-informacional

(SANTOS, 1996). Na medida em que os sistemas técnicos se expandem, numa tendência de unificação técnica dos lugares, ${ }^{12}$ se exige, ao mesmo tempo, um sistema normativo adequado às suas possibilidades. Ambos, sistemas técnicos e sistema normativo indissociáveis na organização do espaço geográfico contemporâneo -, atuam no sentido de possibilitar a realização máxima dos processos de acumulação de capital numa dimensão planetária. Destarte, o meio técnico-científico-informacional torna-se "a cara geográfica da globalização" (SANTOS, 1996, p. 191). Esse meio contribui para alargar o processo de internacionalização do capital, pois as grandes corporações realizam a sua produção em espaços cada vez mais integrados, que incorporam parcelas territoriais de distintos Estados nacionais aos seus circuitos produtivos. São, como afirma Santos (1996), os denominados espaços da globalização.

Castillo (2001, p. 242) pondera que "as novas tecnologias da informação possibilitam às grandes firmas e aos Estados dispor de estratégias socioespaciais que inexistiam até então". As condições atuais abrem a possibilidade de um fracionamento cada vez maior da produção, ao mesmo tempo, permite um controle mais centralizado das ações de comando (BENKO, 1999; SANTOS, 1996).

\footnotetext{
12 Milton Santos (1996, p. 154-155) escreve que, no período atual, as técnicas "se difundiram universalmente, ainda que com diferente intensidade e seus efeitos se fazem sentir, direta ou indiretamente, sobre a totalidade dos espaços. Esse, aliás, é um dos caracteres distintivos da técnica atual [...]. Pode-se falar de unicidade técnica pelo fato de que os sistemas técnicos hegemônicos são cada vez mais integrados, formando conjuntos de instrumentos que operam de forma conexa".
}

Desde o final da década de 1970, o Brasil apresentava grandes dificuldades para a manutenção de suas políticas de crescimento econômico. ${ }^{13}$ Segundo Cano (2000), muitos países, como medida para sair da crise, optaram por reformas políticas de corte neoliberal, propugnadas pelos centros hegemônicos: governo dos Estados Unidos, FMI e BIRD. Tais reformas apregoavam, em síntese, uma reorientação do papel do Estado na perspectiva do desenvolvimento.

Desenha-se, portanto, uma nova configuração normativa do Estado brasileiro, numa espécie de simbiose entre as instituições públicas e os agentes privados, voltada a acelerar a modernização do território nacional. A criação do Programa Nacional de Desestatização (PND), na década de 1990, insere-se como um desses elementos.

Promoveu-se, assim, uma vigorosa transformação na formação socioespacial brasileira, sendo o BNDES uma das principais instituições organizadoras desse processo.

O Mapa 4 mostra os desembolsos do BNDES. Nota-se, como nos mapas anteriores, uma concentração de financiamentos nos estados da Região Concentrada, com forte participação do Banco no fomento do processo de privatização.

13 Cabe, neste ponto, uma distinção entre as concepções de crescimento e desenvolvimento econômicos. Celso Furtado (1979) diferencia-os da seguinte forma: o primeiro, crescimento econômico, refere-se ao aumento de produção, isto é, do fluxo de renda dentro de um setor ou subconjunto econômico especializado; o segundo, desenvolvimento, abarcar o primeiro fenômeno, mas se diferencia no que tange as suas repercussões no conjunto da economia. A finalidade do desenvolvimento, segundo o autor, seria a possibilidade plena de realização do homem, e não somente a maior racionalidade e eficiência dos sistemas econômicos. 
Mapa 4 - Desembolsos do BNDES entre 1990 e 2002

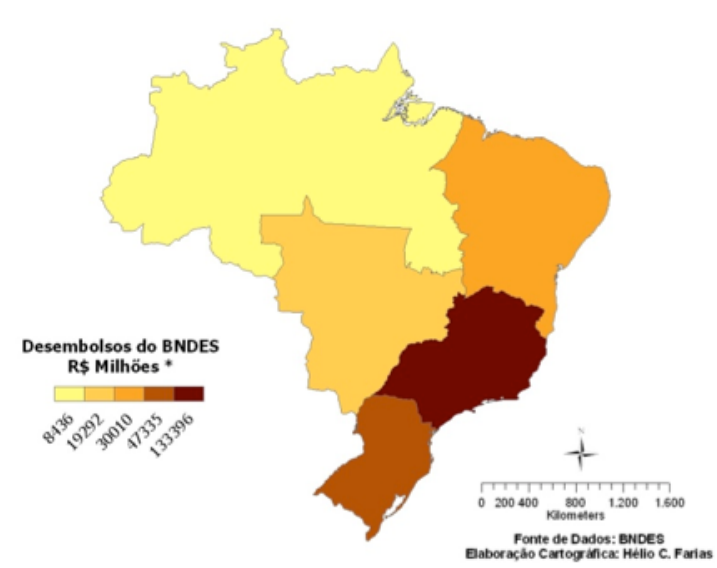

Nos mapas acima, observa-se que as transformações territoriais intensificadas a partir da metade do século passado, com processo de industrialização e a difusão do meio técnico-científico, consolidaram a formação de uma Região Concentrada no território nacional, a despeito das políticas de políticas de planejamento territorial que visavam "corrigir" as disparidades regionais.

Com as novas estratégias de inserção competitiva do Brasil no mercado internacional, sendo as privatizações um de seus correlatos, o controle político e econômico do território, através de instrumentos de planejamento governamental, está se esvaindo.

Segundo Furtado (1992), a formação de um sistema econômico nacional, que estava em curso desde a década de 1930, foi minado pelos projetos autoritários a partir da década de 1960, "atropelado" pelas transformações mundiais ocorridas na década de 1970 e, por fim, interrompido pelas reformas neoliberais da década de 1990.

Com as privatizações nota-se uma profunda reorganização do território brasileiro, sobretudo com redefinição do papel do Estado em setores historicamente estratégicos para o planejamento territorial e, consequentemente, para a manutenção da hegemonia estatal na organização do território.

Como argumenta Diniz (1999), as privatizações promoveram um aumento das desigualdades socioespaciais no território brasileiro. Na Região Concentrada, ${ }^{14}$ ampliou-se a possibilidade de modernizações base material do território, tendo em vista a atração de novos investimentos produtivos, ao passo que nas demais regiões, exceto nos espaços de modernizações pontuais, a presença estatal, mediante grandes projetos, foi minada.

As privatizações representaram, portanto, a perda de instrumentos importantes de planejamento do Estado, pois segundo Vainer (2007, p. 4) os grandes projetos setoriais - minerais, metalúrgico, petroquímicos, energéticos, entre outros foram importantes vetores do planejamento territorial, uma vez que foram decisivos para articular uma "forma muito particular de integração nacional, ao gerarem nexos entre o núcleo urbano-industrial do Sudeste e o resto do país".

Atualmente, o poder de organização territorial está diretamente ligado às grandes empresas. Desse modo, corrobora-se, num sentido amplo, que as privatizações das empresas e dos serviços estatais representam a própria privatização do

\footnotetext{
${ }^{14}$ De acordo com Santos e Silveira (2001, p. 27), a Região Concentrada coincide com a área contínua de manifestação do meio técnico-científico-informacional, ao passo que nas demais regiões do país tal manifestação ocorre de maneira mais seletiva e pontual. A Região Concentrada abrange os estados do Rio Grande do Sul, Santa Catarina, Paraná, São Paulo, Rio de Janeiro, Minas Gerais e Espírito Santo.
} 
território (SANTOS; SILVEIRA, 2001; TOZI, 2005; VAINER, 2007).

A busca pela inserção competitiva nos mercados internacionais, projeto do qual as privatizações foram um correlato, acirra o caráter desigual da formação socioespacial, uma vez que os lugares já industrializados, e, agora, amplamente privatizados, requerem elevados investimentos privados e estatais para aumentarem a sua produtividade, eficiência e competitividade.

Observa-se no gráfico abaixo, apenas como exemplo, a evolução dos financiamentos do BNDES para o fomento das exportações no período pós 1990. O Banco concedeu em 1991 US\$32,8 milhões para o apoio às privatizações, em 2006 este valor saltou para US\$6.376,4 bilhões.

Gráfico 1 - Evolução anual dos desembolsos BNDES - apoio às exportações

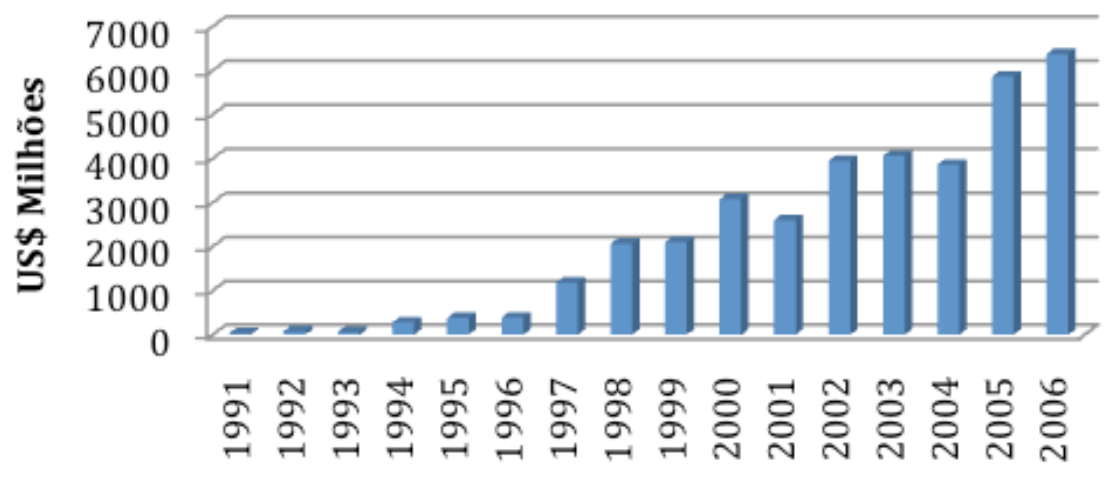

Fonte: BNDES (2008).

Entre 1992 e 2003, o BNDES concedeu mais US\$15,6 bilhões para as empresas privatizadas ou que o governo federal deixou de ser o acionista principal. Dentre os setores que mais receberam empréstimos, destacam o de transportes US\$ 4,5 bilhões ( $29 \%$ do total de empréstimos), seguido pelo de telecomunicações $\mathrm{S} \$ 3,7$ bilhões (24\% do total), siderurgia, com US\$ 3,5 bilhões $(22,5 \%)$; elétrico, com US\$ 3 bilhões (19\%); e, por fim, o petroquímico, com US\$ 831 milhões (5,5\%) (CABRAL; SOUZA, 2004).

Os dados acima exacerbam aquilo que Oliveira (1999, p. 68) denomina falsa consciência da desnecessidade do público. Para o autor, a ideologia da privatização se objetivou "pela chamada falência do Estado, pelo mecanismo da dívida pública interna, onde as formas aparentes são as de que o privado, as burguesias emprestam ao Estado: logo, o Estado, nessa aparência, somente se sustenta como a extensão do privado". O processo real, como afirma o próprio autor, é o inverso, pois é a riqueza pública que em grande parte continua sustentando a reprodução do capital e recrudescendo o uso corporativo do território.

Numa tentativa de sintetizar a problemática do desenvolvimento nacional por nós trabalhada, apresenta-se, no Quadro 1, um esforço de análise dos principais vetores de organização do território, bem como os circuitos produtivos, os sistemas de ações públicos e o papel do BNDES, tendo por referência dois grandes períodos da formação socioespacial brasileira. 
Quadro 1 - Periodização do desenvolvimento nacional

Projeto de integração nacional orientado por uma política de substituições de importações

\title{
Organização do Território
}

\author{
Planejamento territorial como um \\ Investimentos e projetos que \\ buscavam reduzir as disparidades \\ regionais. \\ Esforço de articulação da economia \\ nacional. \\ Tendência de formação de \\ especializações produtivas decorrentes \\ da tradição histórica dos lugares e \\ regiões.

\section{instrumento de alocação dos macrossistemas técnicos que promoviam uma incipiente integração \\ nacional.}

\section{Projeto de integração competitiva orientado por uma estratégia de inserção competitiva nos mercados internacionais}

Planejamento territorial "estratégico" como um instrumento de desarticulação das relações de complementaridade entre as regiões; "cisão" do pacto federativo mediante a acirrada disputa entre cidades, regiões e estados pela atração de investimentos.

Aumento das disparidades tanto nas áreas do meio técnico-científico-informacional, quanto entre a Região Concentração e demais região do país. Maior integração vertical dos lugares mediante as solidariedades organizacionais

Maior tendência de fragmentação territorial, mediante a criação dos espaços nacionais da economia internacional.

Tendência a ampliação das especializações produtivas com os fronts agrícolas e com os Arranjos Produtivos Locais voltados às demandas do mercado externo (especializações regressivas).

Proeminências dos investimentos estatais em setores estratégicos e/ou que demandavam grandes recursos governamentais (indústrias de base, telecomunicações, bélico, siderurgia)

\section{Circuitos Produtivos}

Desenvolvimento associado, estratégia do tripé: Estado, empresa nacional privada e empresas multinacionais.

Produção em grande parte voltada ao mercado interno.

Criação de um quadro normativo voltado ao fortalecimento da estrutura territorial nacional.

Sistemas de Ações Públicos Exemplos: Plano de Metas, PNDs da década de 1970.

Formação de uma burocracia nacional

Elemento central de planejamento, operacionalização e financiamento de grandes planos nacionais de desenvolvimento, a exemplo do Plano de Metas e os PNDs da década de 1970.

Papel do BNDES

Prioridade de financiamento das indústrias de bens de capital e de infraestrutura indispensáveis a integração nacional e a formação de um mercado interno.
Intensa transnacionalização dos sistemas produtivos.

Ampliação dos circuitos espaciais produtivos e dos círculos de cooperação para um escala global de comando. Predomínio das estratégias das empresas multinacionais.

Produção local voltada para o mercado internacional.

Quadro normativo favorável a transnacionalização do território nacional.

Exemplo: Programa Nacional de Desestatização.

Articulação da burocracia estatal com o modus operandi dos mercados.

Elemento central de planejamento e operacionalização do Programa Nacional de Desestatização.

Gestor do Fundo Nacional de Desestatização.

Prioridade de financiamentos para as empresas com unidades produtivas no Brasil, visando incrementar a produtividade, a eficiência e a competitividade, no intuito de acirrar a internacionalização da produção. 


\section{Considerações finais}

O BNDES se destacou como umas das principais instituições governamentais de apoio à industrialização e à integração do território nacional. Todavia, o ritmo e a grandiosidade dos investimentos nos macrossistemas técnicos, sobretudo entre as décadas de 1950, 1960 e 1970, fizeram com que os governos recorressem ao intenso endividamento externo. A partir da década de 1980, com a exaustão de um ciclo de desenvolvimento pautado na política de substituição de importações, a preocupação com o "equilíbrio" das contas externas passou a ser a prioridade no delineamento das políticas nacionais. Sendo assim, as preocupações com a integração do território, com a formação do mercado interno e com a correção das disparidades territoriais foram marginalizadas, senão substituídas, pelas políticas econômicas preconizadas pelos centros hegemônicos, notadamente FMI e Banco Mundial.

As privatizações emergiriam, assim, como um mecanismo capaz de reformar o Estado, dotando-o de uma nova capacidade de intervenção, aproximando-o da lógica de administração das grandes empresas, daí a crescente participação das empresas de consultoria em funções estratégias que antes eram de exclusividade do Estado.

A perda do controle nacional sobre as empresas e bancos contribuiu para desarticular a coordenação estratégica da economia brasileira. De acordo com Belluzzo (2002) o setor produtivo estatal num país periférico funciona como provedor de externalidades positivas, as privatizações e a ampliação da desnacionalização tiraram o dinamismo da economia do controle estatal.
No Brasil, com a introdução do neoliberalismo, predomina a falta de coordenação política para as programas nacionais de desenvolvimento e ocorrem, assim, intervenções pontuais para atender os interesses imediatistas dos setores privados, havendo um estreitamento entre o que, genericamente, pode-se chamar de "Políticas dos Estados" e as "Políticas das Empresas". A força política deste discurso atual cria dificuldades teóricas e práticas para retomar os debates sobre a "questão nacional", bem como visa excluir do debate político a ideia de projeto nacional como elemento organizador dos anseios sociais e coordenador dos elementos essenciais à promoção do desenvolvimento e da equidade social.

Considera-se, portanto, que o planejamento governamental ao abdicar da tarefa de pensar e instrumentalizar um projeto autônomo de desenvolvimento subordina-se politicamente as estratégias das grandes empresas para organizar o território. O planejamento territorial situa-se, assim, como um elemento estratégico, que busca dinamizar os lugares e regiões já inseridos nos circuitos produtivos da "economiamundo". É o que pode ser observado com a trajetória do BNDES na década de 1990, pois a princípio, o Banco imbuiu-se da responsabilidade de conduzir o processo de privatização e, depois, passou a financiar empresas com unidades produtivas no Brasil, no intuito com aumentarem sua participação nas exportações mundiais.

A atuação recente do BNDES contribuiu para ampliar o uso corporativo do território, uma vez que os circuitos de produtivos estão, agora, privatizados e, em grande medida, desnacionalizados. 


\section{Referências bibliográficas}

ALÉM, A. C. D. BNDES: papel, desempenho e desafios para o futuro. Rio de Janeiro: BNDES, Textos para Discussão, n. 62, 1997.

BATISTA, J. C. O BNDES e o desenvolvimento brasileiro. In: VELLOSO, J. P. R.; ALBUQUERQUE, R. C. (Orgs.). A promoção do desenvolvimento: os 50 anos do BNDES e do Banco do Nordeste. Rio de Janeiro: José Olympio, 2003.

BECKER, B. K.; EGLER, C. A. G. Brasil: uma nova potência regional na economiamundo. Rio de Janeiro: Bertrand Brasil, 1998.

BELLUZO, L. G. Brasil, um desenvolvimento difícil. In: CASTRO, A. C. Desenvolvimento em debate: novos rumos do desenvolvimento no mundo. Rio de Janeiro: BNDES, 2002.

BENKO, G. Economia, espaço e globalização. 2. ed. São Paulo: Hucitec, 1999.

BNDES. BNDES: 50 Anos de Desenvolvimento. Rio de Janeiro: BNDES, 2002.

BNDES. Estatísticas operacionais do sistema BNDES. Rio de Janeiro: BNDES, 2008. Disponível em: <http://www.bndes.gov.br >. Acesso em: 23 abr. 2013.

CABRAL, O.; SOUZA, L. Governo injeta US\$ 15,6 bi em privatizadas. Folha de S.Paulo, São Paulo, 18 jan. 2004.

CANO, W. Soberania e política econômica na América Latina. Campinas: Editora Unesp/Unicamp, 2000.

CASTILLO, R. A. Tecnologias da informação e os novos fundamentos do espaço geográfico. In: DOWBOR, L.; IANNI, O.; RESENDO, P.; COSTA, H. (Orgs.). Desafios da comunicação. Petrópolis: Vozes, 2001.

COSTA, K. F. Mudança de rumo, mesma função: o BNDES na segunda metade dos anos 80. Dissertação (Mestrado em Ciências Sociais) Pontifícia Universidade Católica, São Paulo, 2003.
CURRALERO, C. R. B. A atuação do sistema BNDES como instituição financeira de fomento no período 1952-1996. Dissertação (Mestrado em Economia) - Universidade Estadual de Campinas, Campinas, 1998.

DIAS, J. L. O BNDE e o Plano de Metas 1956-61. BNDES, Rio de Janeiro: BNDES, 1996, p. 31-141.

DINIZ, A. N. BNDES: de agente de desenvolvimento a gestor da privatização - 1952-2002. Dissertação (Mestrado em Economia) - Universidade Estadual de Campinas, Campinas, 2004.

DINIZ, C. C. Impactos territoriais da abertura externa, privatizações e reestruturação produtiva no Brasil In: V Seminario Internacional de la RII. Toluca, México, 1999.

FARIAS, H. C. O BNDES e as privatizações no uso do território brasileiro. Dissertação (Mestrado em Geografia) - Universidade Estadual de Campinas, 2008.

FURTADO, C. Brasil: a construção interrompida. São Paulo: Paz e Terra, 1992.

. Teoria e política do desenvolvimento econômico. 7. ed. São Paulo: Nacional, 1979.

MARTINS, L. Estado capitalista e burocracia no Brasil pós-64. Rio de Janeiro: Paz e Terra, 1991.

MONTEIRO FILHA, D. C. O BNDES e seus critérios de financiamento industrial: 1952 a 1989. BNDES: um banco de ideias - 50 anos refletindo o Brasil. Rio de Janeiro: BNDES, 2002.

MORAES, A. C. R. Território e história no Brasil. São Paulo: Annablume, 2002.

MOURÃO, J. O. A integração competitiva e o planejamento estratégico do Sistema BNDES. Revista do BNDES, n. 2, 1994.

NAJBERG, S. Privatização dos recursos públicos: os empréstimos do sistema BNDES ao setor privado nacional com 
correção monetária parcial.

Dissertação (Mestrado em Economia) - Pontifícia Universidade Católica, Rio de Janeiro, 1989.

OLIVEIRA, F. Privatização do público, destituição da fala e anulação da política: o totalitarismo neoliberal. In: OLIVEIRA, F.; PAOLI, M. C. (Orgs.).

Os sentidos da democracia: políticas do dissenso e hegemonia global. Petrópolis: Vozes/Brasília: Nedic, 1999. p. 55-82.

PINTO, M. A. C. O BNDES e o sonho do desenvolvimento: 30 anos de publicação do II PND. Revista do BNDES. Rio de Janeiro, v. 11, n. 22, 2004, p. 51-79.

SANTOS, M. A natureza do espaço: técnica e tempo, razão e emoção. São Paulo: Hucitec, 1996.

. A urbanização brasileira. São Paulo: Hucitec, 1993.

; SILVEIRA, M. L. O Brasil: território e sociedade no início do século XXI.
Rio de Janeiro: Record, 2001.

SILVA BERNARDES, A. M. A contemporaneidade de São Paulo: produção de informações e novo uso do território brasileiro. Tese (Doutorado em Geografia) Faculdade de Filosofia, Letras e Ciências Humanas, Universidade de São Paulo, São Paulo, 2001.

SILVA JR., G. BNDES: importante ordenador do território brasileiro. Dissertação (Mestrado em Geografia) Universidade Federal Fluminense, Rio de Janeiro, 2004.

TOZI, F. As privatizações e a viabilização do território como recurso.

Dissertação (Mestrado em Geografia)

- Universidade Estadual de

Campinas, Campinas, 2005.

VAINER, C. Fragmentação e projeto nacional: desafios para o planejamento territorial. In: XII Encontro da Associação Nacional de Pósgraduação e Pesquisa Urbana e Regional (Anpur). Belém, 2007. 